\title{
PERFIL DAS PROPRIEDADES LEITEIRAS PERTENCENTES AO PROGRAMA CURRAL BONITO DO MUNICÍPIO DE RIO POMBA, MG
}

\section{Profile of the dairy properties belonging to the "Curral Bonito" program, municipality of Rio Pomba, MG, Brazil}

\author{
Iago Lúcio Cruz Melo ${ }^{1 *}$, Rafael Monteiro Araújo Teixeira ${ }^{I}$
}

\begin{abstract}
RESUMO
O objetivo do presente estudo foi avaliar os índices zootécnicos e a qualidade do leite de produtores pertencentes ao programa Curral Bonito. O experimento foi realizado durante os meses de março a outubro de 2016, utilizando-se 17 propriedades leiteiras localizadas no município de Rio Pomba, pertencente à mesorregião da Zona da Mata Mineira. A avaliação consistiu na aplicação de um questionário, para levantamento da propriedade. Os itens avaliados foram parâmetros de composição (\% gordura e proteína), padrões higiênico-sanitários (contagem de células somáticas - CCS) e índices zootécnicos. Foram constatados que os teores de gordura e proteína estavam dentro do padrão permitido pela IN62. Em relação à CCS, foram encontrados valores acima dos limites permitidos pela legislação. Ao diagnosticar o perfil das propriedades, verificou-se que os produtores pertencentes ao programa Curral Bonito necessitam além da melhoria do potencial genético dos animais, o acompanhamento por assistência técnica especializada, com adoção de estratégias capazes de reduzir os custos de produção, aumentando a produtividade e consequentemente a lucratividade da propriedade.
\end{abstract}

Palavras-chave: qualidade do leite; contagem de células somáticas; ordenha; alimentação animal.

1 Instituto Federal de Educação, Ciência e Tecnologia Sudeste de Minas Gerais (IFSUDESTEMG), Campus Rio Pomba, Avenida Dr. José Sebastião da Paixão, Lindo Vale, 36180-000, Rio Pomba, MG, Brasil.

E-mail: iago_ed@hotmail.com

* Autor para correspondência. 


\begin{abstract}
We evaluated zootechnical indexes and milk quality from "Curral Bonito" Program producers. A survey was applied to each owner during March and October of 2016 using 17 properties from Rio Pomba municipality, belonging to the mesoregion of Zona da Mata Mineira. We evaluated the fat and protein percentage, hygienicsanitary standards (CCS) and zootechnical indexes. It was found that fat and protein contents were within the standard allowed by IN62. With respect to CCS, values were above the limits allowed by the legislation. As a conclusion, it is verified that the producers of "Curral Bonito" program need, besides animals genetic improvement, to be monitored by specialized technical assistance in order to adopt strategies to reduce production costs, increase productivity and, trerefore, the profitability of the properties.
\end{abstract}

Keywords: milk quality; somatic cell count; milking; feeding animal.

\section{INTRODUÇÃO}

Compreende-se que o Brasil é o quinto maior país produtor de leite do mundo, atrás apenas dos EUA, Índia, União Europeia e China (IBGE, 2014). A atividade leiteira está presente em 5.564 municípios brasileiros (CARVAlHO et al., 2013). No entanto, entre os principais países produtores de leite do cenário mundial, o Brasil apresenta o maior rebanho leiteiro, apesar da baixa produtividade. Em contraste, países como Estados Unidos e a Nova Zelândia com efetivo de rebanho equivalente ou menor, possuem três a quatro vezes mais a capacidade de produção por vaca (SOUTO et al., 2009).

Segundo IBGE (2014), o município de Rio Pomba - MG possui produção de leite de 11.545.000 litros/ano, com rebanho de aproximadamente 6.300 vacas em lactação. Portanto, para que os pecuaristas deste município continuem contribuindo com a produção de um produto de qualidade, tornase extremamente necessária a higiene antes, durante e depois da ordenha.

No contexto da produção de leite e da busca pela qualidade no município de Rio Pomba - MG foi criado o projeto "Curral Bonito", que tem por objetivo desenvolver o rebanho com alto padrão genético, visando o aumento da produção e produtividade, resgatando a vocação agropecuária leiteira do município. Mas no mundo competitivo, a produção de leite vai além de litros diários e é preciso qualidade para que a indústria, o produtor e a sociedade tenham reais benefícios. Diante dos fatos, estudar o impacto do projeto Curral Bonito na qualidade do leite no município de Rio Pomba-MG é uma demanda constante.

A produção de leite de boa qualidade é uma exigência do mercado consumidor, uma necessidade para a indústria de laticínios e a garantia de permanência no mercado para os produtores leiteiros (PINTO, 2009). A busca por alimentos saudáveis, por uma melhor qualidade de vida e por uma dieta mais adequada vem revelando ao cenário mundial um aumento no consumo de leite e derivados lácteos, ao lado de uma crescente preocupação com a qualidade desses alimentos (SILVA; SOUZA, 2006).

Segundo Hartmann et al., (2006), para a melhoria da qualidade microbiológica do leite e para seu melhor aproveitamento industrial, é imprescindível que a sua temperatura diminua no menor tempo possível após a ordenha, sendo a utilização do pré-resfriador de placas antes do resfriador final, uma alternativa eficiente e viável. 
O leite de qualidade se baseia em diversos parâmetros, incluindo a composição físico-química, baixa contagem de células somáticas (CCS), baixa contagem padrão em placa (CPP), ausência de adulterantes e níveis aceitáveis de antibiótico. Nesse cenário, o Ministério da Agricultura, Pecuária e Abastecimento (MAPA), publicou a Instrução Normativa $n^{\circ} 62$ (BRASIL, 2011) que atualizou alguns aspectos da Instrução Normativa do MAPA n ${ }^{\circ} 51$, de 18 de setembro de 2002 (BRASIL, 2002), e aprovou o novo Regulamento Técnico de produção, identidade e qualidade dos leites tipo A, cru refrigerado e pasteurizado, além do Regulamento Técnico da coleta de leite cru refrigerado e seu transporte a granel.

A Instrução Normativa $n^{\circ} 62$ (BRASIL, 2011) é a legislação que determina limites que definem a qualidade de leite no Brasil, sendo que a CCS e a CPP varia conforme a região brasileira. Com isso são realizadas análises para identificar se os níveis em que se encontram o leite produzido pelos produtores estão dentro dos padrões recomendados pela Portaria $n^{\circ} 56$ (BRASIL, 1999). Segundo a IN 62 as regiões Centro-Oeste, Sudeste e Sul a partir de 01/07/2016 e as regiões Norte e Nordeste a partir de 01/07/2017 têm que obter um decréscimo de células somáticas esperado de 400.000 células/ml, sendo este considerado o limite de CCS presente no leite.

Como o leite é um alimento nobre, o estudo de sua qualidade em termos regionais é essencial para gerar informações à população, à indústria e ao produtor para que busque o sucesso da atividade pecuária. Além disso, como o município de Rio Pomba - MG possui o programa Curral Bonito que vem há muitos anos contribuindo para a melhoria da genética de gado leiteiro. Entende-se que avaliar como essa genética influencia os índices zootécnicos e a qualidade é crucial para trabalhos de desenvolvimento rural sustentável.
Assim, objetivou-se avaliar o perfil das propriedades e a qualidade do leite dos produtores pertencentes ao programa Curral Bonito, no município de Rio Pomba, Minas Gerais de acordo com a IN62.

\section{MATERIAL E MÉTODOS}

O estudo foi realizado no município de Rio Pomba, localizado na mesorregião da Zona da Mata de Minas Gerais. O município caracteriza-se pelo clima do tipo subtropical úmido (segundo definição de Koppen-Geiger: Cwa) com temperatura anual variando de $15,3{ }^{\circ} \mathrm{C}$ a $27,9^{\circ} \mathrm{C}$, área territorial de $252,418 \mathrm{Km}^{2} \mathrm{e}$ altitude máxima de 910 metros e mínima de 419 metros (INMET, 2016).

Foram escolhidas 17 propriedades aleatoriamente pertencentes ao programa Curral Bonito, desenvolvido pela Secretaria de Agricultura do município de Rio Pomba, MG. Para que fosse feito o levantamento da propriedade, foi realizada a aplicação de questionário semi-estruturado, onde se abordou assuntos relacionados a índices zootécnicos e qualidade do leite como: rebanho total; planejamento genético; sistema de ordenha; utilização de volumoso e concentrado; sistema de produção; forma de armazenamento do leite; se possuem controle de qualidade; se recebem por qualidade do leite; se utilizam alguma medida preventiva contra mastite. $\mathrm{O}$ levantamento foi realizado durante os meses de março a maio de 2016.

Após a realização do levantamento, foram coletadas amostras de leite das propriedades que possuíam tanques de expansão e latão de leite, no período de junho a julho de 2016, sendo acondicionadas em frascos plásticos com conservantes (Bronopol ${ }^{\circledR}$ ) e posteriormente acondicionadas em um isopor com gelos descartáveis, mantendo assim uma temperatura entre $2{ }^{\circ} \mathrm{C}$ à $6{ }^{\circ} \mathrm{C}$, por no máximo 48 horas e encaminhadas para o Laboratório de Análises de Qualidade de Leite da 
Embrapa Gado de Leite no município de Juiz de Fora - MG, para fins de análises dos teores de proteína bruta, gordura, lactose, extrato seco total, contagem de células somáticas.

A determinação da composição centesimal do leite cru foi feita pela técnica de infravermelho (IR) com transformada de Fourier (FT), em que as moléculas de gordura, proteína e lactose absorvem radiação infravermelho em comprimentos de onda distintos, de acordo com os grupos funcionais presentes nas moléculas. Baseado nisso, o software do equipamento calcula a concentração dos componentes usando modelos de calibração multivariada (IDF, 2013). A determinação de contagem de células somáticas foi determinada por equipamento eletrônico Bentley Combi System 2300 ${ }^{\circledR}$ (BENTLEY..., 1998), calibrado com amostras padrão de leite cru.

Os produtores foram distribuídos de acordo com o volume de leite diário da propriedade, sendo separados em três grupos:

Grupo 1: constituído de 6 produtores produzindo de 100 a 200 litros/leite/dia;

Grupo 2: constituído de 5 produtores produzindo de 200 a 300 litros/leite/dia;

Grupo 3: constituído de 6 produtores produzindo acima de 300 litros/leite/dia.

Os dados obtidos foram tabulados e submetidos à análise descritiva levando em consideração o volume de leite produzido.

\section{RESULTADOS E DISCUSSÃO}

De acordo com a Tabela 1, foi possível verificar que a relação vacas em lactação/rebanho total em todos os níveis de produção encontra-se abaixo do recomendado, índice este que, de acordo com Lins e Vilela (2006) é entre $60 \%$ a $65 \%$. Estes dados indicam a falta de orientação técnica, resultando assim em baixa produtividade, comprometendo a lucratividade dos produtores, visto que são elas a principal fonte de renda. A relação vacas em lactação/total de vacas dos três níveis de produção analisados apresentou porcentagem inferior a $83 \%$ de vacas em lactação, que é o valor considerado ideal para que a propriedade apresente uma eficiência viável à produção segundo Lins e Vilela (2006).

O número de animais em recria está alto, devido alguns produtores optarem por recriar machos mestiços, funcionando como uma reserva financeira em momentos de crise. Para que haja uma melhora significativa na produtividade e lucratividade da propriedade, os produtores devem diminuir o número de animais em recria ou até mesmo vacas secas. Este índice elevado de vacas secas pode estar relacionado à menor eficiência reprodutiva do rebanho, o que acarreta a grandes intervalos de partos. Consequentemente menos vacas em lactação e menor número bezerros nascidos.

Tabela 1 - Total de vacas no rebanho, número de vacas em lactação, porcentagem de vacas em lactação de acordo com o nível de produção em litros/leite/dia

\begin{tabular}{lcccc}
\hline \multicolumn{1}{c}{ Nível de Produção } & 100 a 200 & 200 a 300 & $>300$ & Média \\
\hline Rebanho Total & 31 & 54 & 104 & 63 \\
Vacas em Lactação & 13 & 19 & 37 & 23 \\
Vacas Secas & 7 & 7 & 15 & 10 \\
Recria & 14 & 27 & 52 & 31 \\
\hline VL/ VT (\%) & 65 & 73 & 71 & 70 \\
VL/ RT (\%) & 42 & 35 & 36 & 37 \\
\hline
\end{tabular}

$\mathrm{VL}=$ vacas em lactação; $\mathrm{VT}=$ vacas totais; $\mathrm{RT}=$ rebanho total. 
Visto que o programa Curral Bonito é pautado no melhoramento genético via inseminação artificial, acredita-se que é necessário treinar mais os produtores quanto à observação de cio, pois essa compromete toda eficiência reprodutiva.

Assim, uma maneira de minimizar esse problema seria a utilização de acompanhamento técnico, permitindo melhor eficiência da tecnologia adotada, aumentando a eficiência reprodutiva que é um dos fatores que mais contribui para melhorar o desempenho e lucratividade dos rebanhos leiteiros. O ideal seria a produção de uma cria/ ano, com intervalos de partos de 12 a 12,5 meses e períodos de lactação de 10 meses, ocorrendo uma perfeita interação dos parâmetros genéticos, reprodutivos, sanitários e nutricionais (SOUSA et al., 2013).

Avaliando sistemas de produção, uma das técnicas que de forma geral contribui para a evolução genética é o uso de sêmen. De acordo com o levantamento realizado, $76,53 \%$ dos produtores entrevistados utilizam sêmen ofertado pela prefeitura e $24,47 \%$ utilizam sêmen próprio, ou seja, adquiridos diretamente de empresas (Tabela 2).

Pode-se observar que uma pequena parte dos produtores com níveis de produção acima de 200 litros de leite buscam a melhoria de seu rebanho, comprando sêmen de empresas particulares, dando ênfase ao melhoramento genético, visando melhorar a eficiência na produção de seu rebanho.

De acordo com a Associação Brasileira de Inseminação Artificial - ASBIA (2016) ao longo de 2015 em Minas Gerais, a utilização da inseminação artificial na pecuária de leite abrangeu 14,6\% das vacas, índice que é considerado pequeno frente ao tamanho do rebanho estadual. Desta forma, a porcentagem de produtores que fazem a utilização de inseminação artificial no município de Rio Pomba pode ser considerada superior à média do estado de Minas Gerais, embora a eficiência reprodutiva esteja baixa, ou seja, há poucas vacas em lactação em relação ao total de vacas.

Nos produtores de 100 a 200 litros/leite/ dia, alguns ainda não possuem conhecimento do quanto é favorável à melhoria do seu rebanho para o aumento de sua produção e consequentemente o aumento da rentabilidade mensal utilizando um planejamento genético adequado. Mas, verifica-se que o programa Curral Bonito têm trazido progressos para o município, pois, $89 \%$ dos produtores entrevistados possuem planejamento genético.

$\mathrm{O}$ planejamento genético visa acasalamentos realizados produzindo fêmeas para iniciar a produção em aproximadamente 3 anos, almejando a melhoria do rebanho como um todo, consequentemente aumentando os sólidos do leite, gordura e proteína e melhorando ainda resultados em facilidade

Tabela 2 - Diagnóstico de utilização de sêmen e planejamento genético de acordo com o nível de produção em litros/leite/dia

\begin{tabular}{lcccc}
\hline \multicolumn{1}{c}{ Nível de Produção } & 100 a 200 & 200 a 300 & $>300$ & Média \\
\hline Sêmen Utilizado & $(\%)$ & $(\%)$ & $(\%)$ & $(\%)$ \\
\hline Prefeitura & 100 & 60,00 & 67,60 & 76,53 \\
Próprio & - & 40,00 & 33,40 & 24,47 \\
\hline Planejamento Genético & & & & \\
\hline Sim & 67,00 & 100 & 100 & 89,00 \\
Não & 33,00 & - & - & 11,00 \\
\hline
\end{tabular}


de partos (características reprodutivas) e persistência em lactação. Há produtores que além de buscar melhorias na produção, visam à morfologia animal, procurando melhor conformação de úbere e melhores aprumos, esperando assim obter vida produtiva mais longa em seus animais.

O sistema de produção predominante entre os produtores entrevistados é o sistema semiconfinado (pasto + volumoso ofertado no cocho) com $83,33 \%$ dos produtores de acordo com os dados da Tabela 3. Sendo assim, o produtor utiliza a pastagem vinculada com o volumoso ofertado no cocho, barateando o custo de produção.

Em relação ao tipo de alimentação adotado para o rebanho conforme descrito na Tabela 4, muitas vezes as propriedades utilizam mais de um tipo de volumoso. Sendo assim, 46,67\% dos produtores, utilizam silagem de milho na alimentação do seu rebanho; $11,10 \%$ utilizam cana e capim; $18,90 \%$ utilizam silagem de milho e cana; $5,57 \%$ utilizam silagem de milho com capim; $11,10 \%$ utilizam silagem de milho, cana e capim e $6,67 \%$ utilizam silagem de capim e cana.

Observou-se que a maioria dos produtores utilizam como complementação na dieta volumosa de seu rebanho a cana de açúcar, certamente visando minimizar os custos na alimentação, visto também que essa forrageira

Tabela 3 - Sistemas de produção utilizado na propriedade leiteira baseado no nível de produção em litros/leite/dia

\begin{tabular}{lcccc}
\hline \multicolumn{1}{c}{ Nível de Produção } & 100 a 200 & 200 a 300 & $>300$ & Média \\
\hline Sistemas de Produção & $(\%)$ & $(\%)$ & $(\%)$ & $(\%)$ \\
\hline Pasto & 33,33 & - & - & 11,11 \\
Semi Confinado & 50,00 & 100 & 100,0 & 83,33 \\
Confinado & 16,67 & - & - & 5,56 \\
\hline
\end{tabular}

Tabela 4 - Utilização de diferentes tipos de volumosos e concentrados utilizados pelos produtores de acordo com o nível de produção

\begin{tabular}{lcccc}
\hline \multicolumn{1}{c}{ Nível de Produção } & 100 a 200 & 200 a 300 & $>300$ & Média \\
\hline Volumoso & $(\%)$ & $(\%)$ & $(\%)$ & $(\%)$ \\
\hline Silagem de Milho & 16,70 & 40,00 & 83,30 & 46,67 \\
Cana/Capim & 33,30 & - & - & 11,10 \\
S.M/Cana & - & 40,00 & 16,70 & 18,90 \\
S.M/Capim & 16,70 & - & - & 5,57 \\
S.M/Cana/Capim & 33,30 & - & - & 11,10 \\
S.C/Cana & - & 20,00 & - & 6,67 \\
\hline Concentrado Comercial & & & & \\
\hline Sim & 66,66 & 60,00 & 50,00 & 58,89 \\
Não & 33,34 & 40,00 & 50,00 & 41,11 \\
\hline
\end{tabular}

S.M $=$ Silagem de Milho; S.C $=$ Silagem de Capim. 
possui grande produtividade em períodos críticos do ano como no período seco. Segundo Rangel et al. (2010) o uso de cana-de-açúcar na alimentação de ruminantes tem importância cada vez maior no Brasil, tendo em vista a redução do custo da alimentação sem perdas expressivas no desempenho animal.

E em relação à suplementação concentrada, 58,89\% dos produtores afirmam utilizar concentrado comercial na dieta do rebanho. Como o programa Curral Bonito é voltado na maioria para pequenos produtores, verifica-se que a grande maioria desses produtores adotam o concentrado comercial (Tabela 4). Entre os produtores que produzem mais de 300 litros/dia, 50\% já elaboram seu próprio concentrado. Ou seja, verifica-se que a medida que o volume de leite aumenta, os produtores tendem a fabricar seu próprio concentrado. Essa estratégia é interessante, pois elaborar o próprio concentrado pode ser uma ferramenta para baratear custos de produção, mas também demanda critérios técnicos e de logísticas.

Em relação ao sistema de ordenha, observa-se que $71 \%$ das propriedades analisadas utilizam o sistema de ordenha tipo balde ao pé, enquanto $16,67 \%$ utilizam a ordenha manual no rebanho e $12,33 \%$ utilizam ordenha tipo espinha de peixe (Tabela 5).

Quanto ao local de armazenamento do leite $64,43 \%$ dos entrevistados possuem tanque de expansão individual. Diversos autores relacionam a qualidade do leite às condições em que o leite foi produzido na propriedade, bem como ao processamento, transformação, armazenamento e distribuição adequada do leite e do produto final. Com isso, o leite obtido em condições de higiene, com menor contato com o ambiente e armazenado em temperatura adequada, apresenta melhor qualidade (NERO et al., 2009; SILVA et al., 2008).

De acordo com Zafalon et al. (2008) os locais de produção de leite não devem

Tabela 5 - Identificação de procedimentos básicos referentes à qualidade do leite de acordo com o nível de produção em litros/leite/dia

\begin{tabular}{lcccc}
\hline \multicolumn{1}{c}{ Nível de Produção } & 100 a 200 & 200 a 300 & $>300$ & Média \\
\hline Tipo de Ordenha & $(\%)$ & $(\%)$ & $(\%)$ & $(\%)$ \\
\hline Manual & 50,00 & - & - & 16,67 \\
Mecânica (B.P) & 50,00 & 80,00 & 83,00 & 71,00 \\
Mecânica (E.P) & - & 20,00 & 17,00 & 12,33 \\
\hline Tanque de Expansão & & & & \\
\hline Coletivo & 66,70 & 40,00 & - & 35,57 \\
Individual & 33,30 & 60,00 & 100 & 64,43 \\
\hline Controle Mastite & & & & 53,33 \\
\hline Sim & 50,00 & 60,00 & 50,00 & 46,67 \\
Não & 50,00 & 40,00 & 50,00 & \\
\hline Teste da Caneca & & & & 58,90 \\
\hline Sim & 66,70 & 60,00 & 50,00 & \\
Não & 33,30 & 40,00 & 50,00 & \\
\hline
\end{tabular}

B.P = Balde ao pé; E.P = Espinha de Peixe. 
conter substâncias nocivas que possam afetar a qualidade do produto. O leite deve ser protegido contra excrementos, secreções ou resíduos de origem animal e não se deve produzi-lo em lugares onde a água constitua risco à saúde do consumidor, deve-se evitar ainda o acúmulo de fezes e a proliferação de moscas. Também se recomenda que haja uma pessoa responsável pela retirada das fezes, que não seja o ordenhador, devendo-se evitar a construção de esterqueiras muito próximas ao local de ordenha.

Em relação ao controle para monitoramento de casos de mastite, 53,33\% dos produtores afirmaram realizar alguma medida de prevenção. Em relação ao teste de caneca, $41,10 \%$ dos produtores afirmam não realizar esta prática, demonstrando assim, o reduzido número de proprietários rurais que estão conscientizados com a produção de um leite de qualidade e com a sanidade do úbere. Sendo assim, a baixa taxa de utilização de métodos de monitoramento do controle de mastite encontrada nos resultados desta pesquisa, demonstra a necessidade de uma ampla divulgação de informações sobre os benefícios econômicos e sanitários que envolvem a produção do leite com qualidade, devido à incidência de mastite clínica e subclínica variar de acordo com o grau de higiene e tecnificação da produção de leite.

Segundo Netto et al. (2009), a mastite é uma das doenças mais caras na produção leiteira sendo sua prevalência relativamente alta. A alta prevalência da mastite decorre desta enfermidade possuir uma diversidade de fatores envolvidos levando a grande dificuldade em controlá-la, bem como erradicá-la.

O controle da mastite é um dos principais fatores que precisam ser levados em consideração quando se deseja produzir um leite de alto padrão de qualidade e aceitação. De acordo com Muller (2002), os programas de prevenção e controle da mastite têm por objetivo limitar a prevalência das infecções e por consequência diminuir os impactos econômicos na atividade leiteira. Um bom programa de controle deve ter como metas principais, erradicar as mastites contagiosas, manter baixos os índices de mastites ambientais e contagens de células somáticas.

Ainda com relação aos indicadores de qualidade do leite, avaliando as medidas de controle de mastite nos rebanhos, 55,67\% dos entrevistados afirmaram utilizar o pré-dipping em suas propriedades (Tabela 6), sendo este um procedimento de desinfecção dos tetos antes da ordenha, considerado como método eficaz no controle da mastite ambiental, com uma taxa de redução em até $50 \%$ de novas infecções (MULLER, 2002). Não há dúvida que o método mais eficiente é o de imersão das tetas em solução desinfetante antes da ordenha. Quanto ao uso do pós-dipping, prática realizada para a desinfecção dos tetos ao final da ordenha e, considerada importante no controle de novas infecções intramamárias, $50 \%$ dos produtores afirmam realizá-la. Em relação a estes tratamentos para vaca seca, $76,67 \%$ dos entrevistados afirmam realizar esta prática.

Em relação ao pagamento por qualidade descrito na Tabela 7, 83\% dos produtores afirmam não receber bonificação pela melhoria do produto.

Segundo Santos (2005), o pagamento por qualidade não depende de novas normas, uma vez que estes programas consistem no pagamento de bonificação para o produtor que fornece a matéria-prima com características diferenciadas, o que gera retorno para a indústria e consumidor. Isto se configura essencialmente como um acordo entre fornecedor e comprador, devendo, todavia, ser consideradas as várias peculiaridades de cada indústria e de cada região. Observa-se que as indústrias na região não estão visando uma bonificação adequada para os produtores, mesmo estes melhorando o seu produto de alguma forma. 
Os constituintes do leite, avaliados estão descritos na Tabela 8. Ao avaliar a qualidade das amostras de leite coletadas, pode-se perceber que os percentuais se enquadram na IN62 (gordura $>3 \%$, proteína $>2,9 \%$, lactose $>4,3 \%$, extrato seco desengordurado $>8,4 \%$ ).
Os teores de gordura diferem do encontrado por Camilo (2014), que obteve teores de gordura de até $3,01 \%$ ao avaliar a qualidade do leite no município de Guarani, $\mathrm{MG}$, região próxima a Rio Pomba, MG.

Tabela 6 - Utilização de procedimentos higiênicos adotados durante a ordenha de acordo com o nível de produção em litros/leite/dia

\begin{tabular}{lcccc}
\hline Nível de Produção & 100 a 200 & 200 a 300 & $>300$ & Média \\
\hline Pré-Dipping & $(\%)$ & $(\%)$ & $(\%)$ & $(\%)$ \\
\hline Sim & 67,00 & 50,00 & 50,00 & 55,67 \\
Não & 33,00 & 50,00 & 50,00 & 44,33 \\
\hline Pós-Dipping & & & \\
\hline Sim & 50,00 & 33,00 & 67,00 & 50,00 \\
Não & 50,00 & 67,00 & 33,00 & 50,00 \\
\hline T.M.S & & & \\
\hline Sim & 67,00 & 80,00 & 83,00 & 76,67 \\
Não & 33,00 & 20,00 & 17,00 & 23,33 \\
\hline
\end{tabular}

T.M.S $=$ Tratamento de Mastite na Secagem dos Animais.

Tabela 7 - Levantamento de pagamento por qualidade de acordo com o nível de produção

\begin{tabular}{lcccc}
\hline Nível de Produção & 100 a 200 & 200 a 300 & $>300$ & Média \\
\hline Recebe por Qualidade & $(\%)$ & $(\%)$ & $(\%)$ & $(\%)$ \\
Sim & 16,70 & - & 33,00 & 16,57 \\
Não & 83,30 & 100 & 67,00 & 83,43
\end{tabular}

Tabela 8 - Qualidade média do leite em função do nível de produção de litros/leite/dia

\begin{tabular}{lcccc}
\hline \multicolumn{1}{c}{ Nível de Produção } & 100 a 200 & 200 a 300 & $>300$ & Média \\
\hline PML & 122 & 282 & 740 & 381 \\
Gordura (\%) & 4,50 & 3,78 & 4,39 & 4,22 \\
Proteína (\%) & 3,26 & 3,31 & 3,33 & 3,30 \\
Lactose (\%) & 4,48 & 4,53 & 4,53 & 4,51 \\
ESD (\%) & 8,68 & 8,74 & 8,76 & 8,73 \\
CCS $\left(\times 10^{3} / \mathrm{ml}\right)$ & 1145 & 626 & 1149 & 973 \\
\hline
\end{tabular}

PML: Produção Média de Leite; ESD: Extrato Seco Desengordurado; CCS: Contagem de Células Somáticas. 
Em relação à CCS encontrada, todas as faixas estudadas estão em desacordo com a IN62, que estabelece contagens máximas de $400 \mathrm{mil} \mathrm{CCS} / \mathrm{ml}$. Pode-se afirmar que existem algumas falhas ao realizar todas as boas práticas de ordenha que previnem o aumento significativo de CCS no leite. A média encontrada neste estudo foi de $973 \times 10^{3} / \mathrm{ml}$ que em relação a IN62 encontra-se acima do limite permitido. Possivelmente entre os produtores do programa Curral Bonito há uma grande quantidade de animais com mastite subclínica, independentemente do tamanho da propriedade.

Esse levantamento mostra que os produtores estão sendo falhos em alguns manejos diários como: teste da caneca do fundo preto, teste para identificação da mastite subclínica (Califórnia Mastit Test - CMT); limpeza de ordenha; desinfecção dos tetos (pré e pós-dipping); diluição dos produtos sanitizantes de maneira equivocada; higiene dos utensílios utilizados e funcionários; estocagem e transporte do leite ou até mesmo falta de assistência técnica especializada. A avaliação da CCS é uma ferramenta de grande importância para averiguar as condições sanitárias do animal, pois o aumento da CCS pode trazer consequências como diminuição na produção de leite e no rendimento de fabricação de produtos lácteos.

Segundo Philpot e Nickerson (1991) há estimativas de perdas de produção de leite/ lactação em função da quantidade de CCS. Assim a estimativa de infecção e perda na produção de leite por lactação dos rebanhos analisados foi em média de $719 \mathrm{~kg} / \mathrm{lactação.}$ Levando em consideração a média paga aos produtores pelo litro de leite de $\mathrm{R} \$ 1,21$ na região de Rio Pomba - MG, estima-se que os produtores deixam de ganhar $\mathrm{R} \$ 870,00$ por lactação.

Observa-se que, de acordo com os dados obtidos neste trabalho, a má higienização dos utensílios de ordenha, tetos e o próprio colaborador, podem ajudar a ocasionar perdas significativas em relação ao aumento da CCS.

\section{CONCLUSÕES}

As propriedades pertencentes ao programa Curral Bonito demandam assistência técnica para melhorar os índices produtivos, independentemente da quantidade de leite produzida diariamente. A qualidade do leite dos produtores atende as normas da IN 62, com exceção da contagem de células somáticas.

\section{REFERÊNCIAS}

ASBIA. Associação Brasileira de Inseminação Artificial. Disponível em: <http://www. asbia.org.br/novo/home/>. Acesso em: 03 nov. 2016.

BENTLEY INSTRUMENTS INC. Bentley 2000 operator's manual. Chaska: Bentley Instruments Inc., 1998. 79 p.

BRASIL. Portaria $n^{\circ} 56$, de 07 de dezembro de 1999. Submete à consulta pública os regulamentos técnicos sobre produção, identidade e qualidade de todos os tipos de leite e coleta de leite cru resfriado e transporte a granel. Diário Oficial da República Federativa do Brasil, Brasília, n. 234, p. 34-49, 8 dez. 1999. Seção 1.

BRASIL. Ministério da Agricultura, Pecuária E Abastecimento. Departamento de Inspeção de Produtos de Origem Animal. Instrução Normativa $n^{\circ} 51$, de 18 de setembro de 2002. Aprova os Regulamentos Técnicos de Produção, Identidade e Qualidade do Leite tipo A, do Leite tipo B, do Leite tipo C, do Leite Pasteurizado e do Leite Cru Refrigerado e o Regulamento Técnico da Coleta de Leite Cru Refrigerado e seu Transporte a Granel, em 
conformidade com os Anexos a esta Instrução Normativa. Diário Oficial da República Federativa do Brasil, Brasília, 20 set. 2002. Seção 1, p. 8-13.

BRASIL. Ministério da Agricultura, Pecuária e Abastecimento. Instrução Normativa $n^{\text {o }}$ 62, de 29 de dezembro de 2011. Aprova o Regulamento Técnico de Produção, Identidade e Qualidade do Leite tipo A, o Regulamento Técnico de Identidade e Qualidade de Leite Cru Refrigerado, o Regulamento Técnico de Identidade e Qualidade de Leite Pasteurizado e o Regulamento Técnico da Coleta de Leite Cru Refrigerado e seu Transporte a Granel, em conformidade com os Anexos desta Instrução Normativa. Diário Oficial da República Federativa do Brasil, 30 dez. 2011. Seção 1, p. 6.

CAMILO, M. G. Utilização de ocitocina em gado de leite. 2014. 40p. Trabalho de Conclusão de Curso (Bacharel em Zootecnia) - Instituto Federal de Educação Ciência e Tecnologia do Sudeste de Minas Gerais Campus Rio Pomba, Rio Pomba, 2014.

CARVALHO, T. B. et al. Estratégia e cenários de consumo de leite no Brasil. XVI SEMEAD, Seminários em Administração. São Paulo, 2013. Disponível em: <http:// sistema.semead.com.br/16semead/resultado/ an_resumo.asp?cod trabalho $=470>$. Acesso em: 14 set. 2017.

HARTMANN, W. et al. Inibição da flora mesofílica do leite cru através de sistemas de refrigeração. Paraná, 2006. Disponível em: <http://www.terraviva.com.br/IICBQL/ p051.pdf>. Acesso em: 14 set. 2017.

INMET - INSTITUTO NACIONAL DE METEOROLOGIA. Disponível em $<$ http:// www.inmet.gov.br>. Acesso em: 30 abr. 2016.
INSTITUTO BRASILEIRO DE GEOGRAFIA E ESTATÍSTICA (IBGE). Indicadores IBGE. Estatística da Produção Pecuária, v. 42, junho, 2014.

INTERNATIONAL DAIRY FEDERATION (IDF). International Standard Organization (ISO). BS EN ISO 16297: 2014. Milk Bacterial count. Protocol for the evaluation of alternative methods. 2013. 13 p.

LINS, P. M. G.; VILELA, P. S. Diagnóstico da pecuária leiteira do Estado de Minas Gerais em 2005: relatório de pesquisa. Belo Horizonte, 2006. 156 p.

MÜLLER, E. E. Qualidade do leite, células somáticas e prevenção da mastite. In: II SulLeite: Simpósio sobre Sustentabilidade da Pecuária Leiteira na Região Sul do Brasil, 2002, Maringá. Anais... Maringá: UEM/CCA/ DZO - NUPEL, 2002. 212P.

NERO, L. A. et al. Qualidade microbiológica do leite determinada por características de produção. Ciência e Tecnologia de Alimentos, Campinas, v. 29, p. 386-390, 2009.

NETTO, A. S. et al. Estudo comparativo da qualidade do leite em ordenha manual e mecânica. Revista do Instituto de Ciência da Saúde, v. 27, p. 345-349, 2009.

PHILPOT, W. N.: NICKERSON, S. C. Mastitis: Counter Attack. Naperville: Babson Bros, 1991. 150p.

PINTO, R. T. Mastite: Revisão. 2009. 34 p. Trabalho monográfico (curso de pós-graduação Lato sensu em Higiene e Inspeção de produtos de Origem Animal) - Universidade Castelo Branco, Rio de Janeiro, 2009.

RANGEL, A. H. N. et al. Desempenho e parâmetros nutricionais de fêmeas leiteiras 
em crescimento alimentadas com silagem de milho ou cana-de-açúcar com concentrado. Revista Brasileira de Zootecnia, v. 39, p. 2518-2526, 2010.

SANTOS, M. V. Utilizando a CCS e a CBT como ferramenta em tempos de pagamento por qualidade do leite. In: CARVALHO, M. P.; SANTOS, M. V. (Org.). Estratégia e competitividade na cadeia de produção de leite. Passo Fundo: Berthier, 2005, p. 246-260.

SILVA, S.; SOUZA, C. Avaliação microbiológica de queijo tipo Minas frescal comercializado na cidade de Belém - Pará. Belém: Laboratório Central do Estado do Pará; Centro Tecnológico da Universidade Federal do Pará, 2006.

SILVA, M. C. D. et al. Caracterização microbiológica e físico-química de leite pas- teurizado destinado ao programa do leite no Estado de Alagoas. Ciência e Tecnologia de Alimentos, Campinas, v. 28, p. 226-230, 2008.

SOUZA, G. G. T. et al. Eficiência reprodutiva em bovinos de leite através da monta natural e inseminação artificial. Acta Tecnológica, v. 8, p. 12-18, 2013.

SOUTO, L. I. M. et al. Qualidade higiênico-sanitária do leite cru produzido em propriedades do estado de São Paulo, Brasil. Veterinária e Zootecnia, v. 16, n. 3, p. 491499, 2009.

ZAFALON, L. F. et al. Boas práticas de ordenha, 2008. Disponível em: <https:// www.embrapa.br/busca-de-publicacoes/-/ publicacao/48313/boas-praticas-de-ordenha>. Acesso em: 04 nov. 2016. 